Article

\title{
The Impact of Lead Time Uncertainty on Supply Chain Performance Considering Carbon Cost
}

\author{
Zhuoqun Li ${ }^{1}\left(\mathbb{D}\right.$, Weiwei Fei ${ }^{1}$, Ermin Zhou ${ }^{1}$, Yuvraj Gajpal ${ }^{2}\left(\mathbb{D}\right.$ and Xiding Chen ${ }^{3, *} \mathbb{C}$ \\ 1 School of Transportation and Logistics, East China Jiao Tong University, Nanchang 330013, China; \\ 1901@ecjtu.edu.cn (Z.L.); Phoebe_0814@163.com (W.F.); 0642@ecjtu.edu.cn (E.Z.) \\ 2 Asper School of Business, University of Manitoba, Winipeg, MB R3T 5V4, Canada; \\ yuvraj.gajpal@umanitoba.ca \\ 3 Department of Finance, Wenzhou Business College, Whenzhou 325035, China \\ * Correspondence: chanxd@wzbc.edu.cn
}

Received: 22 September 2019; Accepted: 13 November 2019; Published: 16 November 2019

\begin{abstract}
In supply chain operation practices, lead time uncertainty is a common management issue. Uncertain lead time can lead to increased inventory costs and unstable service levels, which will directly affect the overall operation performance of the supply chain. While considering environmental performance in supply chain, it is important to understand how an uncertain lead time will affect sustainable performance. In this paper, we constructed a supply chain model with stochastic lead time and explored the relationship between uncertain lead time and supply chain performance. We considered carbon cost, inventory cost, and service level as a supply chain performance. System dynamics methodology was employed to observe and explore the dynamic change trend of the overall performance in the complicated supply chain model. This was done under both different levels of lead time standard deviation and different order policies. The results demonstrate how stochastic lead times can significantly increase inventory costs and carbon costs. Therefore, we propose appropriate ordering policies which mitigate the negative impacts of stochastic lead times.
\end{abstract}

Keywords: stochastic lead times; supply chain system performance; order policies; carbon cost

\section{Introduction}

The concept of a low carbon economy has come into existence to cope with numerous environmental challenges. Due to government regulations and public awareness, enterprises have realized the importance of introducing low-carbon operations and sustainability into their management objectives. Agi et al. [1] conducted a study on Australian firms and found two main motives that caused enterprises to shift towards green development. The first motive is to comply with environmental regulations, and the second motive is to achieve a competitive edge. Diabat et al. [2] indicated that the sustainable supply chain management (SSCM) system could ensure environmentally friendly practices in traditional supply chains with essential enablers. On the one hand, government policies and regulations, such as carbon caps, are putting pressure on enterprises to incorporate environmental factors into their business models. On the other hand, a number of enterprises have made sustainable green operations as their competitive advancement. In supply chains, several activities produce carbon emissions, for example, transportation and warehousing. Hence, it is critical to manage and control carbon emissions in supply chain operations.

Global trade boosts have shifted the short-distance supply chain within a country to long distance supply chain between countries [3]. This change has resulted in an increase in the lead time and has accelerated the fluctuation. The lead time is also called replenishment delay, which is the time gap between sending an order and receiving it. Existing studies demonstrate that lead time is a key factor 
that affects supply chain performance [4]. If the lead time is uncertain, the situation is complex from both the cost and service perspectives. Our research is motivated by the growing concern of business, which is forcing business enterprises to reduce carbon emission cost in their supply chain network. Therefore, this paper includes carbon emission costs as one of the supply chain performance indicators. Some studies $[5,6]$ have demonstrated that the uncertain lead time is directly related to supply chain performance. Therefore, this paper examines the effect of uncertain lead time on carbon emission costs. Further, the paper investigates whether the effect of lead time increase on the behavior of carbon cost emissions is the same as the behavior of inventory costs and service levels or not.

When both market demand and lead time are uncertain, the supply chain system becomes more complicated and dynamic with time [7]. The traditional operational method makes it difficult to explore the complicated supply chain system. System dynamics provides a new way to study complex systems. The discipline of system dynamics was founded in 1956 by Professor Forrester of the Massachusetts Institute of Technology. The system dynamics discipline integrates systems theory, cybernetics, information theory, and organization theory with the help of computer technology. The system dynamics model can also show the dynamic behavior of the object system. The system dynamics can be used to better analyze non-linear systems which are caused by many real situations in the supply chain system, such as stochastic lead time, uncertain demand, non-negative order, etc. In this study, we applied a system dynamics method to build a supply chain model and explore the dynamic change trend of supply chain performance indicators, including inventory cost, service level, and carbon cost, under uncertain lead times.

The reminder of this paper is organized as follows: Section 2 presents an overview of the relevant literature. Section 3 presents the assumptions and models and introduces the performance indicators; Section 4 conducts model analysis and numerical simulations. Section 5 focuses on the analysis of experimental results. Finally, Section 6 summarizes the main research conclusions and proposes several future research directions.

\section{Literature Review}

Research was conducted on how to reduce the negative impact on the environment during supply chain operations [8,9]. Quite a number of studies focus on transportation studies [10-12]. This paper mainly discusses the dynamic change of carbon emission cost in an uncertain supply chain environment with stochastic lead time, and explores the inventory management approach to buffer the fluctuation.

In the research on carbon inventory management, the focus has been on newsvendor models and EOQ (economic order quantity) models [13-15]. Song et al. [16] analyzed a newsvendor model and demonstrated that it is possible to achieve multiple targets, including carbon emission reduction, cost saving, and profit improvement at the same time by applying a suitable order policy. Chen et al. [17] also found that there are some conditions under which the reduction in carbon emissions is greater than the increase in cost. Hovelaque et al. [18] presented a novel model which considered the relationship among inventory policy, carbon emissions, and price account. They found that certain environmental policies can significantly decrease total carbon emissions.

Most recent research focuses on different operational factors in the supply chain while simultaneously considering carbon emissions. Benjaafar et al. [19] integrated carbon emissions into supply chain operational process with inventory management, production, and procurement. They also modified traditional models to account for both general cost and carbon emissions. Diabat et al. [20] proposed a genetic algorithm approach for supply chain integration while considering carbon emissions. They considered multiple scenarios such as different demand models and multiple distribution centers. Park et al. [21] investigated punishment mechanism in supply chain structure and found that supply chain members are affected differently by carbon emission reduction. Konur et al. [22] incorporated environmental factors into a supply chain control model with uncertain demand to study the effect of logistics policies and supplier selection on environmental performance. $\mathrm{Xu}$ et al. [23] considered demand preferences in low carbon supply chain management to analyze the effect of consumer 
preference on inventory cost. Hoen et al. [24] studied the effects of transportation facilities on carbon emissions under uncertain demand conditions. They showed that the lead time directly affects carbon emissions on a transport facility. Sarkar et al. [25] reached a similar conclusion. Finally, Arikan et al. [26] studied environmental effects related to lead time uncertainty for transportation facilities.

Recent studies on low carbon inventory management have begun to account for an uncertain lead time effect, but the research in this field is not sufficient. Many existing studies were based on order-up-to-level inventory models. For example, Chatfield et al. [27] studied stochastic lead time and established order-up-to-level inventory models of periodic replenishment. They conducted computer experiments to explore the impact of stochastic lead time on the inventory system. The results showed that the uncertainty of lead time aggravates the fluctuation of ordering quantity. Yet, efficient sharing of quality information is beneficial to reduce the fluctuation. Du et al. [28] extended the demand model to an autoregressive moving average model (ARMA) with independent and identically distributed lead times. However, these two studies both used the order fluctuation as the only evaluation indicator to study the uncertain lead time effect. Many studies added the bullwhip effect as the evaluation index. The bullwhip effect is the magnified effect of the demand information distortion while moving from downstream to upstream in the supply chain. The bullwhip effect states that a small fluctuation in demand at the downstream level (i.e., at a retailer level) creates larger fluctuations in demand at the upstream level (i.e., wholesale, distributor, manufacturer, and raw material supplier levels). In supply chain management, each player has limited information over demand and, thus, the fluctuating demand pattern at any supply chain link influences the entire supply chain with its forecasting inaccuracy (i.e., ordering too much or ordering too less). It is considered to be one of the main factors that weakens supply chain performance, because it creates either excess inventory or shortages in the whole supply chain network. A detailed explanation about the bullwhip effect can be found in the literature [27]. Boute et al. [29] considered both order fluctuation and inventory fluctuation. By conducting numerical simulation experiments, they found that the bullwhip effect and inventory costs can be reduced at the same time. However, this study assumed that the supply chain is linear and that there are no order crossovers. In fact, an in-depth study by Saldanha et al. [30] affirmed that the order crossover is a common phenomenon. Chaharsooghi et al. [31] investigated the bullwhip effect in multi-echelon supply chain models and concluded that random lead time has a greater impact on bullwhip effect over fixed lead time.

Jian et al. [32] considered the influence of the randomness of lead time on the inventory model for perishable drugs. Through empirical and sensitivity analysis, they determined that the weight-distribution values of the shelf life of perishable drugs and the service level are reasonable. Spiegler et al. [33] discussed the influence of lead time uncertainty on order quantity, inventory level, and work-in-process quantity. Assuming demand is stable, they followed the small disturbance principle to probe lead time disturbance related to system output, and they found that the order quantity, inventory level, and work-in-process quantity increase with the lead time. Moreover, the reduction in lead time can result in a dynamic change of damping. This result implies that, although reducing the lead time can improve system performance, a flexible management plan is required to avoid unnecessary system turbulence. The above study provides a theoretical basis for setting up the parameter in this paper. Dejonckheere et al. [34] proved that an order-up-to-level order policy creates a bullwhip effect. However, if two feedback loops are introduced to the order policy, the bullwhip effect can be weakened and, sometimes, even eliminated. This order policy is called APVIOBPCS (automatic pipeline, variable inventory, and order based on production control system). The APVIOBPCS model has two feedback loops to control the order quantity by discrepancies in inventory and work-in-process. In addition, by changing the adjustment parameters, APVIOBPCS policy clusters are generated as various ordering policies. When the adjustment parameters of inventory and work-in-process inventory are both 1, it becomes an order-up-to-level policy. The APVIOBPCS model has been applied in practice and in real time [35-37]. 
This paper differs from the existing studies in the following aspects. First, the model in this paper considers both uncertain demand and uncertain lead time, which is near reality situation. Correspondingly, there is an order crossover phenomenon in the supply chain model which only emerges when lead time is stochastic. These conditions make the model more complex and nonlinear. Second, this paper introduces carbon cost into the supply chain model as a new systematic performance indicator. It compares average cost and average service level change to carbon cost change under varying supply chain environments. This paper also adopts the system dynamics method to discuss the impact of stochastic lead time on supply chain inventory system, and also find more suitable order policies than the traditional order method, which can dampen the negative effect of uncertain lead time.

\section{Inventory Control System Model Considering Stochastic Lead Times}

\subsection{Assumptions}

In order to explore the impact of stochastic lead times on supply chain inventory systems, this paper constructed a three-stage supply chain with a distributor as the focal point in a periodic continuous review system based on the APVIOBPCS model. The proposed model makes the following assumptions:

Assumption 1. At the beginning of a single period, the distributor receives the products from the manufacturer, and the distributor's ordering plan is submitted to the manufacturer at the end of the period; at the same time, the system state is updated.

Assumption 2. The upstream manufacturer has abundant production capacity and can fully meet the orders from the distributor without shortages.

Assumption 3. The downstream retailer demand follows normal distribution $N\left(\mu_{D}, \delta_{D}^{2}\right)$, and the demand of each period may not be fully met due to variable market demand.

Assumption 4. The demand forecasting for the next period is based on the exponential smoothing method, with the smoothing factor $\theta$.

Assumption 5. The distributor supplies products to the retailer with the SFS model (supply from stock). That is, the minimum of demand and current inventory is supplied. The shortage will not be replenished in the current period, and it needs to be submitted by downstream retailer in the next period in the form of new demand orders. Hence, inventory is allowed to take negative value. It is noted that this is consistent with business practice.

Assumption 6. The distributor's orders are subject to non-negative constraints. In business reality, it can be interpreted as not allowing returns.

\subsection{Stochastic lead times}

This paper investigates the influence of stochastic lead times on the performance of supply chain inventory level. While introducing stochastic lead times into the model, it is essential to consider the allowance of order crossover. In order crossover, the sequence of order arrival can be different from the sequence of order placement. Order crossover is due to stochastic lead time. Due to randomness, multiple order batches from several previous periods could arrive in one period at the same time, or the distributor could receive those orders in advance, which are placed in a later period. According to a global logistics survey [38], crossover orders accounted for more than $40 \%$ of total orders. Thus, this paper facilitates the order crossover in the supply chain system.

The logistics data survey in study [38] shows that the lead time distribution is random. Some of the lead time distributions are normal, and some of them are close to normal with long tail. This paper simulates stochastic lead time distributions based on the observations found in the study [38]. We chose several values for standard deviation $\left(\delta_{L}\right)$ to simulate different levels of lead time uncertainty with the same average lead time value $\left(\mu_{L} \approx 2\right)$. Figure 1 shows the four distributions with different standard deviations in our experiments. The symbol $L_{\mathrm{t}}$ represents the corresponding lead time in 
period $t$, with the minimum denoted by 0 and the maximum denoted by $L^{+}$. According to the supply chain event process of this model, a single period in the system starts with the distributor receiving the products from the manufacturer and ends at the distributor issuing the current order plan to the supplier. Submission of the order plan is the last step of each period. Thus, there is a natural delay in the periodic cycle when the distributor receives the homologous products of his order plan. Therefore, the earliest and the latest arrival times of the products in the order plan submitted in period $t$ are recorded as $t+1$ and $t+1+L^{+}$, respectively.

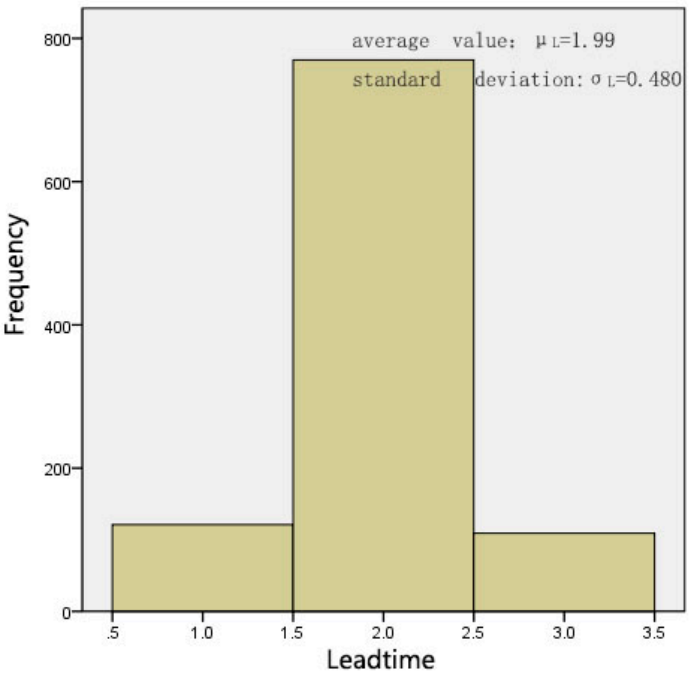

(a)

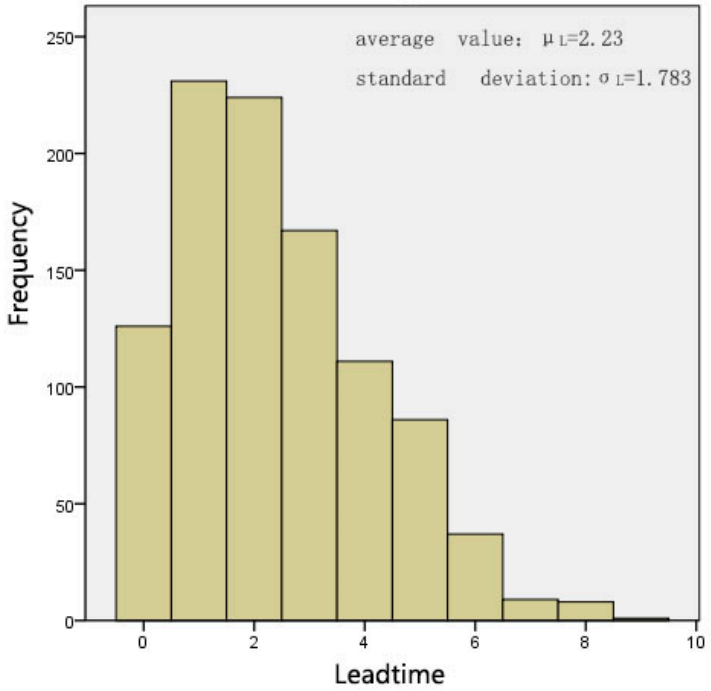

(c)

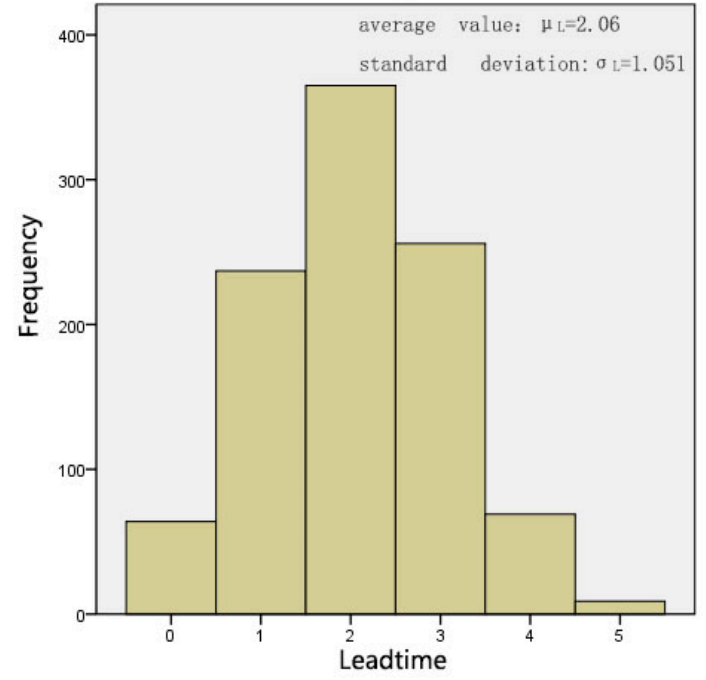

(b)

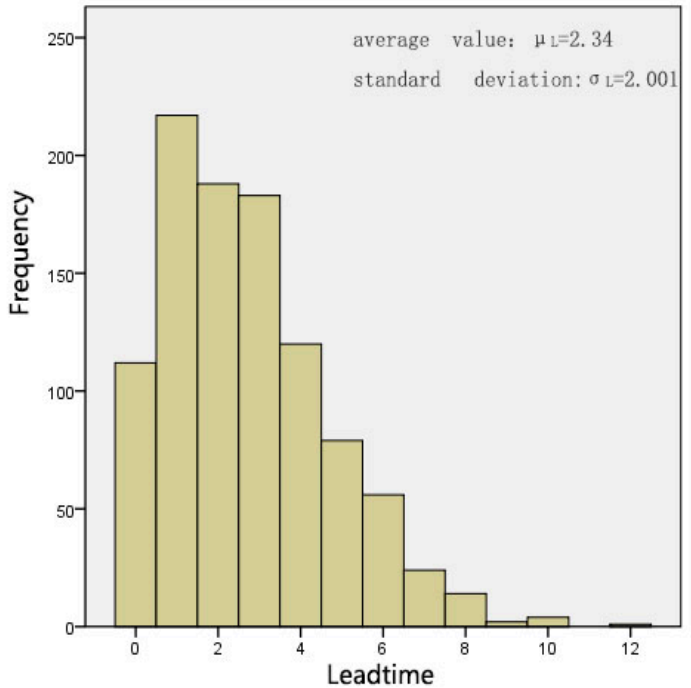

(d)

Figure 1. Stochastic lead time distributions with different standard deviations: (a) average value $\mu_{L}=1.99$ and standard deviation $\delta_{L}=0.480 ;(\mathbf{b})$ average value $\mu_{L}=2.06$ and standard deviation $\delta_{L}=1.051 ;(\mathbf{c})$ average value $\mu_{L}=2.23$ and standard deviation $\delta_{L}=1.783 ;(\mathbf{d})$ average value $\mu_{L}=2.34$ and standard deviation $\delta_{L}=2.001$.

In simulation experiments, the lead time uncertainty can be simulated by the following steps:

Step 1: The distribution of random lead time is assumed in the model. MATLAB is used to generate $\mathrm{n}$ random numbers representing the lead time in the period; these are stored in an array $L$. There are five presumed types of lead time distributions corresponding to five experiments. 
Step 2: Next, the array $L$ is introduced into the basic inventory simulation model, and the delay, corresponding to the order quantity $O Q_{t}$ and determined at the end of the simulation period $t$, is denoted as $L_{\mathrm{t}}$.

Step 3: Since each $L_{t}$ is generated in step 1, the arrival time of $O Q_{t}$ can be calculated at the beginning of each period and recorded in the arrival time array as: $\operatorname{arrivetime}(t)=t+1+L_{t}$.

Step 4: In each period, the arrivetime array from period i to period $i-L^{+}$is checked to determine whether arrivetime $(t)$ equals $i$. If so, the corresponding arrival quantity can be included in the current inventory. Otherwise, it is counted as the work-in-process inventory.

\subsection{Models}

The basic inventory model of this paper is based on the APVIOBPCS (Automatic Pipeline Inventory and Order based Production Control System) model family. The APVIOBPCS model is a collection of inventory policies, which can express different inventory policies with different parameter settings. The common order-up-to-level inventory order policy, which has been used in practice, is also a form of APVIOBPCS.

The core enterprise of the supply chain model in this paper is the distributor. The upstream of the distributor is the manufacturer and downstream is the retailer. According to the principle of the APVIOBPCS production control, the model is assumed to be a periodic review system. The state of each system variable would be updated as the following process.

At the beginning of the period $t$, the distributor receives the previously placed orders. Due to the order crossover as mentioned above, in period $t$, products purchased in multiple historical periods might arrive at the same time, or the distributor may receive the recently ordered products in advance. Accordingly, the arrival quantity $A Q_{t}$ is equal to the sum of orders the manufacturer is delivering $S Q_{t}$ before several periods based on the $L_{t}$, as shown in Equation (1). Then, the distributor can count the inventory $B I N V_{\mathrm{t}}$ at the beginning of period $t$ using Equation (2), which is the sum of the inventory at the end of the last period and the current arrivals.

$$
\begin{gathered}
\text { Arrivals : } A Q_{t}=S Q_{t-L_{i}} \\
\text { Inventory at the beginning: } B I N V_{t}=T I N V_{t-1}+A Q_{t}
\end{gathered}
$$

The distributor delivers the products to the retailer from stock to meet market demand $D_{t}$, and delivery volume $D Q_{t}$ is the minimum of $D_{t}$ and the initial inventory $B I N V_{\mathrm{t}}$ at period $t$, as expressed in Equation (3). If the value of $B I N V_{\mathrm{t}}$ is less than $D_{t}$, stock out $S O Q_{t}$ occurs, which can be calculated using Equation (4). In addition, according to the assumptions in Section 3.3, the shortage $S O Q_{t}$ in the current period would not be fulfilled by the distributor in the next period. When there is a shortage $S O Q_{t}$ in the current period, products are replenished in the form of new demand orders submitted by downstream retailers in the next periods. This policy is consistent with the practice used in many manufacturing industries. Therefore, the shortage $S O Q_{t}$ is not in Equation (3).

$$
\text { Delivery quantity from distributor to market : } D Q_{t}=\min \left(D_{t}, B I N V_{t}\right)
$$

$$
\text { Shortage : } S O Q_{t}=\max \left(0, D_{t}-B I N V_{t}\right)
$$

Equation (5) denotes the ending inventory $\operatorname{TINV}_{t}$ of the period $t$. The ending inventory $\operatorname{TINV}_{t}$ is the minimum of 0 and the difference between the $B I N V_{t}$ and the $D Q_{t}$. The work-in-process inventory $W I P_{t}$ represents the products that have been dispatched by the manufacturer but have not yet reached the distributor. WIP $P_{t}$ can be obtained by subtracting the current arrivals $A Q_{t}$ from the sum of the previous work-in-process inventory $W I P_{t-1}$ and the order quantity $O Q_{t-1}$ using Equation (6). After sending out the demand quantity of the market and ensuring $\operatorname{TIN}_{t}$ and $W I P_{t}$, the next market demand 
$F Q_{t}$ is forecasted. The exponential smoothing method is used to forecast demand with the smoothing factor $\theta$, as in Equation (7).

$$
\begin{gathered}
\text { Terminal inventory : } \operatorname{TINV}_{t}=\max \left(0, B I N V_{t}-D Q_{t}\right) \\
\text { Work- in - process inventory : } \operatorname{WIP}_{t}=W I P_{t-1}+O Q_{t-1}-A Q_{t} \\
\text { Demand forecast : } F Q_{t}=\theta \cdot D_{t}+(1-\theta) F Q_{t-1}
\end{gathered}
$$

Equation (8) reveals the mathematical model of the order policy, which is the key point of the APVIOBPCS model. In order to reduce errors caused by the forecast, two feedback loops were introduced into the model: Adjustment for stock and adjustment for work-in-process. The adjustments for stock and work-in-process inventory discrepancies are represented into the order equation $O Q_{t}$ with the parameters $\alpha_{S}$ and $\alpha_{S L}$, respectively. Hence, $\alpha_{S}$ and $\alpha_{S L}$ are the parameters of the adjustment for $\operatorname{TINV}_{t}$ and $W I P_{t}$, respectively.

$$
\text { Order : } O Q_{t}=\max \left(0, F Q_{\mathrm{t}}+\alpha_{S}\left(\omega \cdot D_{\mu}-T I N V_{t}\right)+\alpha_{S L}\left(L_{\mu} \cdot F Q_{t}-W I P_{t}\right)\right)
$$

The target inventory in the model is denoted by $\left(\omega \cdot D_{\mu}\right)$, where $D_{\mu}$ is the average demand and the parameter $\omega$ is the correlation factor between the target inventory and demand $D_{\mu}$. When $\omega=0$, the target inventory is 0 , and the system achieves the ideal state of "zero inventory". When the lead time is uncertain, the work-in-process inventory cannot be overlooked. It would put an important impact on the overall inventory level and performance of the supply chain. The forecasting demand of the products $F Q_{t}$ and the average lead time $L_{\mu}$ were set as the objective work-in-process inventory to reduce the uncertainty of order decision caused by lead time fluctuation. The parameter combination $\left(\alpha_{S}, \alpha_{S L}\right)$ corresponds to different ordering policies. Earlier research results [39] proved that these parameters and their correlation can impact or determine the stability and performance of a supply chain. Furthermore, when $\alpha_{S}=\alpha_{S L}$, the policy is called a POUT policy, which is used in this paper.

The main variables and parameters of the model are listed in Table 1. The correlation among the variables is shown in an inventory system dynamics model diagram as in Figure 2.

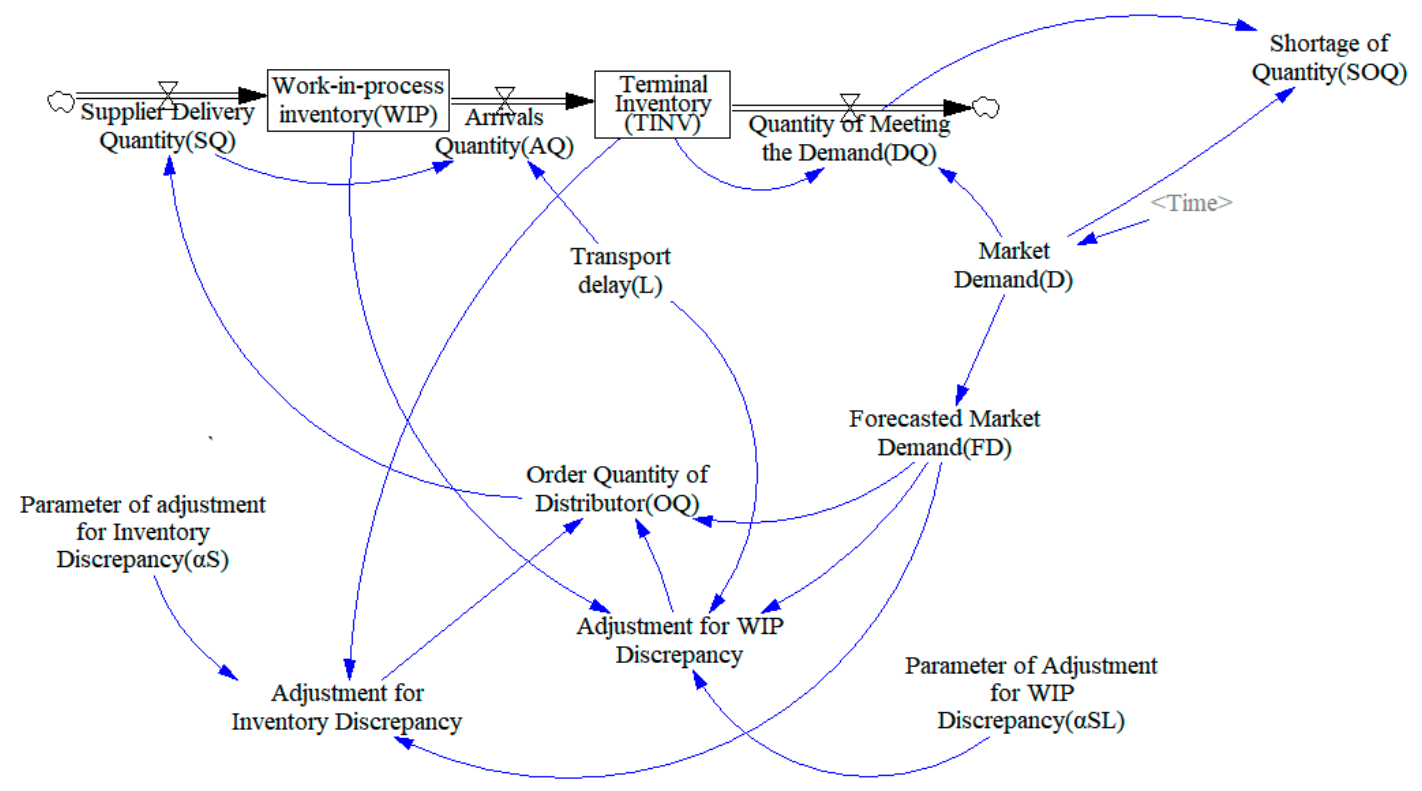

Figure 2. Stock and flow diagram of the model. 
Table 1. Notations in the supply chain inventory model.

\begin{tabular}{|c|c|}
\hline Decision Variables & Description \\
\hline$S Q_{\mathrm{t}}$ & The order quantity of manufacturer delivery in period $t$ \\
\hline$A Q_{\mathrm{t}}$ & The arrival quantity in period $t$ \\
\hline$B I N V_{\mathrm{t}}$ & The inventory at the beginning of the period in period $t$ \\
\hline$T I N V_{t}$ & The terminal inventory in period $t$ \\
\hline$D_{t}$ & The retailer market demand in period $t$ \\
\hline$S O Q_{t}$ & The shortage in period $t$ \\
\hline$W I P_{t}$ & The work-in-process inventory in period $t$ \\
\hline$F Q_{t}$ & The demand forecast in period $t$ \\
\hline$O Q_{t}$ & The order in period $t$ \\
\hline$L_{t}$ & The transport lead time in period $t$ \\
\hline Parameters & Description \\
\hline$\theta$ & The smoothing factor in forecast \\
\hline$D_{\mu}$ & The average market demand \\
\hline$L_{\mu}$ & The average lead time \\
\hline$\alpha_{S}$ & The parameter of adjustment for inventory discrepancy \\
\hline$\alpha_{S L}$ & The parameter of adjustment for WIP discrepancy \\
\hline Performance indicators & Description \\
\hline$C C_{\mathrm{t}}$ & The carbon cost in period $t$ \\
\hline$A C$ & The average inventory cost \\
\hline$A S L$ & The average service level \\
\hline
\end{tabular}

\subsection{System Performance Indicators}

\subsubsection{The Carbon Cost}

In this paper, the carbon cost $C C_{t}$ is introduced as one of the performance indicators for the system, and the system's carbon cost in the model consists of two components. The first component is the transportation carbon cost, and the other is the inventory carbon cost. The transportation carbon cost $T C C_{t}$ mainly comes from the transportation carbon emissions $T P_{t}$ generated by vehicle fuel consumption. Bao et al. [40] proved that the fuel consumption is affected by vehicle load. Equation (9) specifies the mathematical relationship between the fuel consumption per unit distance $P_{t}\left(q_{t}\right)$ and the load $q_{t}$ of a truck under the condition of a non-full load. The fuel consumption in a non-full load and a full-load are denoted as $P_{0}$ and $P^{*}$, respectively. Meanwhile, $Q$ is a constant, emblematizing the maximum load weight of trucks. In the experiment, the total number of trucks $k$ could be calculated from the number of products transported and the weight. According to the Law of Conservation of Elements in chemistry, in a chemical reaction, the kinds and qualities of the elements participating in the reaction remain unchanged. By tracing the carbon atoms in the chemical reaction equation, the carbon emission $P_{c}$ per unit of fuel consumption can be converted. After determining the transportation mileage from the manufacturer to the distributor, the total transport carbon emission $T P_{t}$ can be obtained using Equation (10). Furthermore, according to the carbon emission policies of a few countries and regions, the carbon tax $c c$ is multiplied with $T P_{i}$ to get the transportation carbon cost $T C C_{t}$ using Equation (11).

$$
\begin{gathered}
P_{t}\left(q_{\mathrm{t}}\right)=P_{0}+q_{t}\left(P^{*}-P_{0}\right) / Q \\
T P_{t}=\left((k-1) P^{*}+P_{t}\left(q_{t}\right)\right) \cdot P_{c} \cdot d \\
T C C_{t}=c c \cdot T P_{t}
\end{gathered}
$$

The inventory carbon cost $I C C_{t}$ is the other component of $C C_{t}$. In inventory management, carbon is released by the electrical energy consumption of relevant facilities and equipment, such as refrigeration cabinet, room temperature cabinet, automatic stacker, etc. According to the literature [41], the carbon emission per inventory product can be calculated from the conversion relationship between 
electricity consumption and carbon emissions. In addition, the sensitivity analysis shows that the carbon emissions per product only affect the total cost of inventory carbon emissions, and would not change its fluctuation trend, which is the focus of this paper. In this paper, I $p$ is defined as the inventory carbon cost per product. The inventory carbon cost $I P_{t}$ of the period $t$ can be obtained using Equation (12). Equation (13) represents the total inventory carbon cost ICC $C_{t}$, while Equation (14) aggregates the total carbon cost $C C_{t}$.

$$
\begin{gathered}
I P_{t}=I p \cdot T I N V_{t} \\
I C C_{t}=c c \cdot I P_{t} \\
C C_{t}=T C C_{t}+I C C_{t}
\end{gathered}
$$

\subsubsection{Average Inventory Cost}

Most scholars define the system inventory cost as the combination of inventory holding cost per unit $h$ and shortage cost per unit $b$. This paper adopts the same method for the calculation of inventory cost, as defined in Equation (15).

$$
A C=\frac{1}{n} \cdot \sum\left(h \cdot T I N V_{t}+b \cdot S O Q_{t}\right)
$$

\subsubsection{Average Service Level}

Macchion et al. [42] assumed the service level $S L_{t}$ of each period to be 0 or 1 . In the case of shortages, the service level is considered 0. Otherwise, it is considered 1. In this paper, shortage is introduced to further quantify the service level. As shown in Equation (16), the ratio of shortage $S O Q_{t}$ and demand $D_{t}$ of period $t$ is considered when calculating the service level $S L_{t}$. Furthermore, the average service level $A S L$ is calculated using Equation (17):

$$
\begin{gathered}
S L_{t}=1-S O Q / D_{t} \\
A S L=\frac{1}{n} \cdot \sum S L_{t}
\end{gathered}
$$

\section{Verification and Experimental Design of Simulation Model}

\subsection{Model Verification}

In order to better emulate business practice, a nonlinear model is constructed in this paper. However, it greatly complicates the model, and makes it more difficult to find the optimal analytic solution. Hence, simulation is employed in this paper. In addition, the verification of a simulation model is a vital aspect of using the simulation model. In this paper, the theoretical derivation of the APVIOBPCS model under fixed lead time is used to ensure the correctness of the computer simulation.

Disney et al. [43] showed that the bullwhip effect value $B W V$ changes with the adjustment parameters of in-stock and work-in-process stock, when the lead time is fixed, as shown below:

$$
B W V=\frac{\delta_{O}^{2}}{\delta^{2}}=\frac{T_{W}\left(T_{i}\left(1+T_{i}\left(T_{W}-2\right)+T_{W}\right)-T_{W}\right)}{\left(2 T_{i}-1\right)\left(T_{i} T_{W}\left(3+T_{i}\right)-2 T_{i}^{2}+T_{W}^{2}\left(\left(T_{i}-1\right) T_{i}-1\right)\right)}
$$

where $T_{i}=\frac{1}{\alpha_{S}}$ and $T_{W}=\frac{1}{\alpha_{S L}}$.

Fixed lead time can be regarded as a special case of stochastic lead time. In order to compare with the theoretical value of Equation (18), the standard deviation of lead time in the simulation verification model was set to 0 . The simulation experiment was carried out by MATLAB 2016a to calculate the order fluctuation value under different control parameters. Figure 3 a shows a contour diagram generated by Equation (18), which displays the bullwhip effect value with different parameters under fixed lead 
time and under no order-quantity constraint. Figure $3 \mathrm{~b}$ was generated by simulation experiments, while Figure 3a was generated using theoretical values. Comparing Figure 3a,b shows that the two graphs are basically the same. This means that the simulation results are consistent with the theoretical values, which validates our simulation model.

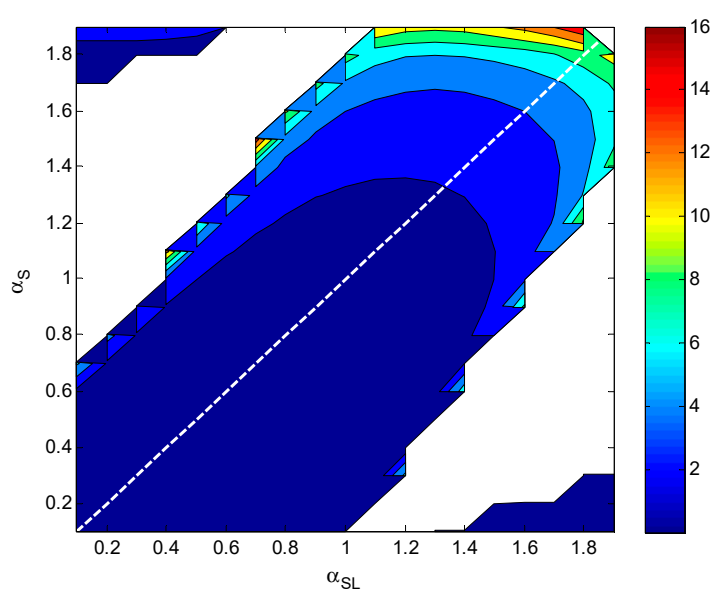

(a)

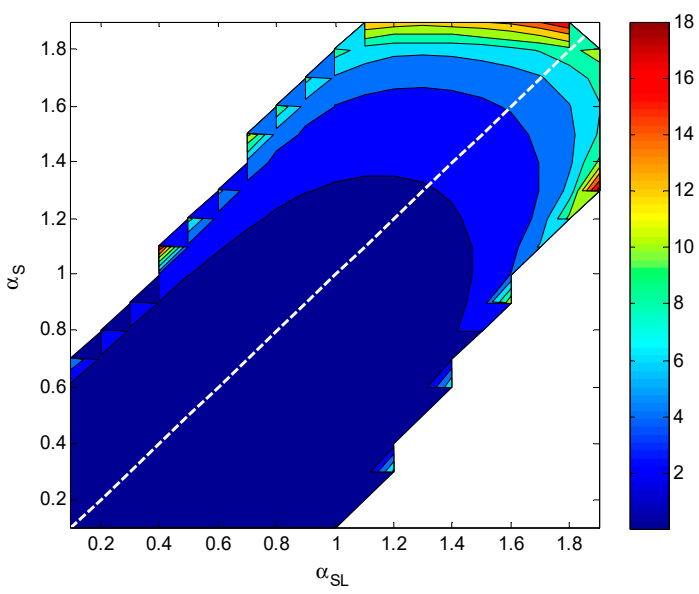

(b)

Figure 3. Comparison of the theoretical (a) and simulative (b) values of order fluctuation.

It is worth mentioning that the top left and bottom right in Figure 3a are different from those in Figure $3 b$. The white parts of the upper triangle and lower triangle areas of the coordinate planes in Figure $3 a, b$ represent the large values or negative bullwhip effect values, which implies poor policies. We drew Figure $3 a$ using MATLAB 2016a according to Equation (18), where we set the program judgement conditions about white area. In our program, the white area represents the places where the bullwhip effect value is larger than 18 or the value is negative. In fact, in Equation (18), if both its numerator and denominator are negative, the bullwhip value is incorrect. However, we omitted this condition intentionally to distinguish the two figures. When we consider the situation where both the numerator and the denominator are negative, the top left and bottom right in Figure 3a show as a white area, and the two figures remain almost same.

\subsection{Model Parameter Analysis}

In this paper, Equations (1)-(8) relate to the decisions of the supply chain. Equations (9)-(17) are mainly used to measure the supply chain performance. There are many parameters in the model, but the most critical parameters can be determined by the transfer function derived from the $z$-transforms of Equations (1)-(8). According to the deduction process shown in the Appendix A, the decision variables are all transformed to the $z$-threshold. Consequently, the system transfer equation between the order $O Q$ and demand $D$ can be obtained as follows:

$$
\frac{O Q(z)}{D(z)}=\frac{z^{L_{t}}\left[\theta\left(1+\alpha_{S L} \cdot L_{u}\right)(z-1) 1 \alpha_{S}(z-\theta+1)\right]}{(z-\theta+1)\left[z^{L^{L}-1} \cdot\left(z+\alpha_{S L}-1\right)+\left(\alpha_{S}-\alpha_{S L}\right)\right]}
$$

Equation (19) shows the stability of the system, which is mainly affected by $\alpha_{S}, \alpha_{S L}$ and $L_{t}, L_{t}$, where $(z-\theta+1)$ represents the stable pole of the system. This deduction further verifies and expands the results reported in [44], which concludes that the parameter combination $\left(\alpha_{S}, \alpha_{S L}\right)$ is the key factor for determining the boundaries among the stability, the stable oscillation, and the exponential oscillation of the system. 


\subsection{Experiment Design}

The model verification and the parameter analysis so far attest that the parameters $\alpha_{S}$ and $\alpha_{S L}$ affect the dynamics of the system, and the various parameter values correspond to different ordering policies. Many researchers have explored the practical impact of the parameter setting on system stability performance with the POUT policy, that is, $\alpha_{S}=\alpha_{S L}$. These researchers argue that POUT policy can improve system stability in a continuous review system [45]. Therefore, this paper adopts the POUT policy, $\beta=\alpha_{S}=\alpha_{S L}$, to explore the effect of stochastic lead times on the inventory system in the range of $[0.1,1.9]$ for parameter $\beta$.

In order to reflect the different levels of lead time uncertainty, this paper assumes that lead time follows stochastic distribution with the average of $\mu_{\mathrm{L}}=2$ and different standard deviations. After a number of trials, five arrays of lead time with standard deviations of $0,0.5,1,1.8$, and 2 were screened. The standard deviation of $\sigma_{L}=0$ represents the fixed lead time. This paper takes the system carbon cost $C C$, average inventory cost $A C$, and average service level $A S L$ as the performance evaluation indicators. Under each lead time distribution, the three performance indicators were observed with the help of MATLAB 2016a. We obtained 15 experiments, as depicted in Table 2, and the experimental results are shown with different order policies in Appendix B.

Table 2. Experiment design.

\begin{tabular}{cccccc}
\hline \multirow{2}{*}{ Performance Indicators } & \multicolumn{5}{c}{ Lead Time Variance } \\
\cline { 2 - 5 } & $\sigma_{L}=\mathbf{0}$ & $\sigma_{L}=\mathbf{0 . 5}$ & $\sigma_{L}=\mathbf{1}$ & $\sigma_{L}=\mathbf{1 . 8}$ & $\sigma_{L}=\mathbf{2}$ \\
\hline Carbon cost & Experiment 1 & Experiment 4 & Experiment 7 & Experiment 10 & Experiment 13 \\
Average inventory cost & Experiment 2 & Experiment 5 & Experiment 8 & Experiment 11 & Experiment 14 \\
Average service level & Experiment 3 & Experiment 6 & Experiment 9 & Experiment 12 & Experiment 15 \\
\hline
\end{tabular}

For minimizing the impact of contingency on the test results, the simulation experiment was conducted for 1000 periods with $\omega=0$. According to the actual survey data, demand obeys the independent random distribution with the mean value of 5021 and the standard deviation of 956.48 . Oliveira et al. [46] proved that the fluctuation of the system is relatively small with a smaller smoothing factor $\theta$. Hence, the demand forecast parameter is set as $\theta=0.4$.

Meanwhile, the values of the constants in the model were set according to the real data obtained from the freight market to ensure the validity of the simulation experiments, as listed in Table 3.

Table 3. The values of experimental parameters.

\begin{tabular}{cccc}
\hline Parameters & Description & \multicolumn{2}{c}{ Value } \\
\hline$b$ & Shortage cost per unit & 9 & $($ yuan/per unit) \\
$h$ & Inventory holding cost per unit & 1 & $(\mathrm{~kg} / \mathrm{per}$ unit) \\
$q$ & Weight of a products & 10 & $(\mathrm{yuan} / \mathrm{per}$ unit $)$ \\
$c c$ & Carbon tax & 0.04 & $(\mathrm{~L} / \mathrm{km})$ \\
$P_{0}$ & No-load fuel consumption of trucks & 0.186 & $(\mathrm{~kg} / \mathrm{L})$ \\
$P_{c}$ & Carbon emissions of oil consumption per unit & 2.61 & $(\mathrm{~kg})$ \\
$Q$ & Maximum load weight of truck & 5000 & $(\mathrm{~kg} / \mathrm{per} \mathrm{unit)}$ \\
$I p$ & Carbon emissions of per unit inventory & 0.5 & $(\mathrm{~L} / \mathrm{km})$ \\
$P^{*}$ & Full-load fuel consumption of trucks of one kilometer & 0.2 & $(\mathrm{~km})$ \\
$d$ & Total mileage of transportation & 1000 & \\
\hline
\end{tabular}

\section{Analysis of Experimental Results}

\subsection{Effect of Stochastic Lead Times on System Performance}

Figure $4 a-c$ depicts carbon costs, average inventory costs, and average service levels with the system adjustment parameter $\beta$ under different lead times and standard deviations $\sigma_{L}$. It can be seen that the values of performance indicators change significantly with different uncertainty degree of 
the lead time. When the standard deviation of lead time $\sigma_{L}$ increases, the average inventory cost and carbon cost decreases, while the average service level increases. However, the change patterns of the three performance indicators are different. With the increase of the parameter $\beta$, the carbon cost decreases initially, and then rises smoothly. The average inventory cost is positively correlated with the parameter $\beta$, while the average service level is negatively correlated with the parameter $\beta$.

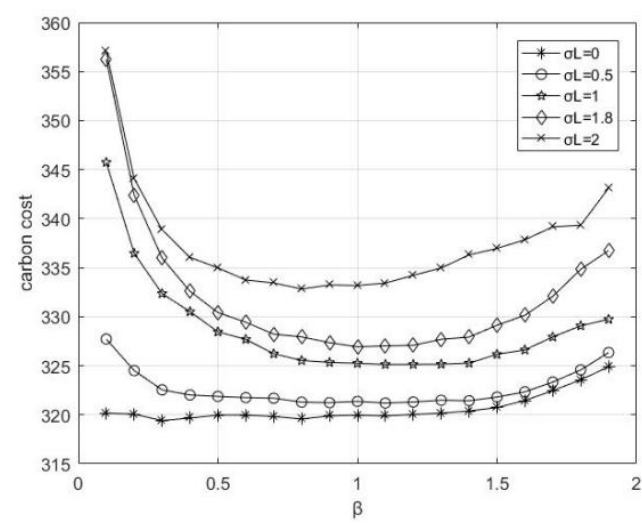

(a) Carbon cost as a function of $\beta$.

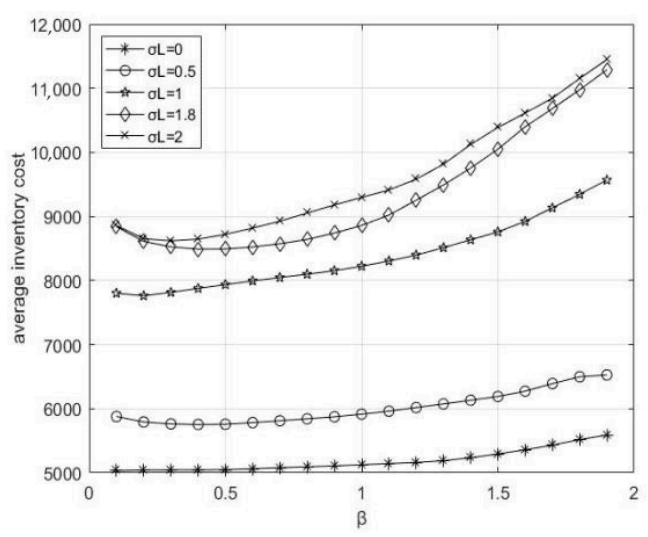

(b) Average inventory cost as a function of $\beta$.

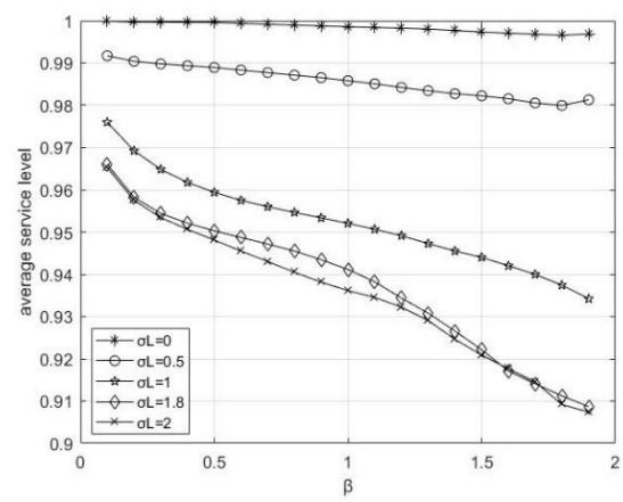

(c) Average service level as a function of $\beta$.

Figure 4. The performance indicators as a function of $\beta$.

We now discuss the rate of change for each performance indicator caused by the stochastic lead times. The change rate is expressed in the form of growth rate as $I R$ and $A I R$ represents the average growth rate of the three indicators in Table 4. Overall, when the standard deviation of lead time increases, the IR of the carbon cost $C C$ and the average inventory cost $A C$ remain positive, while the average service level $A S L$ remains negative. In other words, higher lead time uncertainty deteriorates the performance of the inventory system. The lead time uncertainty negatively affects $A C$, whose average growth rate AIR reaches $17.25 \%$, as shown in Table 4 . In addition, the effect of random lead time on $A S L$ is slightly greater than that on the $C C$, and the average growth rates are $-1.62 \%$ and $1.29 \%$, respectively.

Table 4 shows that the greater the lead time uncertainty, the greater the change rate of the performance indicators. For the carbon $\operatorname{cost} C C$, when the standard deviation of lead time $\sigma_{L}$ increases to 0.5 , the growth rate IR remains $0.62 \%$. However, when $\sigma_{L}$ increases from 0.5 to 2 , the change rate of CC for all stages remains above $1 \%$. The IR decreases initially, and then rises. This implies that lead time uncertainty will lead to an increase in $C C$, but the rate of cost increase will fluctuate. When the $\sigma_{L}$ changes from 0 to 1 , average inventory cost $A C$ and average service level $A S L$ rises to $39.32 \%$ and $3.38 \%$, respectively. Then, as the fluctuation of lead time intensifies, the rates keep declining. In the transition range of $1.8-2$, they fall to $2.82 \%$ and $0.23 \%$, respectively. The results summarized in Table 4 are consistent with what Figure 4 shows. 
Table 4. The rates of change in performance indicators.

\begin{tabular}{cccc}
\hline \multirow{2}{*}{$\sigma_{L}$} & \multicolumn{3}{c}{ IR (\%) } \\
\cline { 2 - 4 } & $\begin{array}{c}\text { Carbon Cost } \\
(C C)\end{array}$ & $\begin{array}{c}\text { Average Cost } \\
(\text { AC) })\end{array}$ & $\begin{array}{c}\text { Average Service Level } \\
(\text { ASL) }\end{array}$ \\
\hline $0-0.5$ & 0.62 & 15.81 & -1.28 \\
$0.5-1$ & 1.86 & 39.32 & -3.38 \\
$1-1.8$ & 1.05 & 11.04 & -1.58 \\
$1.8-2$ & 1.64 & 2.82 & -0.23 \\
AIR $(\%)$ & 1.29 & 17.25 & -1.62 \\
\hline
\end{tabular}

\subsection{Effect of Stochastic Lead Times on Order Decision}

In this subsection, we focus on the relationship between stochastic lead times and inventory systems. It can be observed from Figure 4 that when the standard deviation of lead time $\sigma_{L}$ increases from 0 to 0.5 , the curves of carbon cost $C C$, average inventory cost $A C$, and average service level $A S L$ remain relatively smooth, and they are least affected by the change of parameter $\beta$. In contrast, when $\sigma_{L}$ increases from 1 to 2 , these three performance indicators change significantly. In particular, the average inventory cost $A C$ and average service level $A S L$ continue to rise and fall with the increase of parameter $\beta$. However, the carbon cost curve shows a completely different trend. Figure 4 a shows that when $\sigma_{L}$ is small, the curve remains roughly smooth, which indicates that when the lead time is short, the parameter has little influence on carbon cost. In contrast, with an increase in $\sigma_{L}$, the minimum point of the curve gradually decreases, and the decision-making area of ordering is reduced. Hence, there exists an optimal order policy to minimize carbon costs. This observation implies that lead time uncertainty influences the adjustment of ordering decisions on carbon cost.

Appendix B is a data table of a computer simulation experiment, which reveals inventory system performance indicators for different standard deviations of lead time and different $\beta$ values. In comparison, the variance of $A C$ is the largest, followed by the variance of $C C$, which is then followed by the variance of $A S L$-and this ranking is not impacted by different values of the standard deviations. Regardless of the uncertainty degree of lead time, the average inventory cost $A C$ is most affected by the parameter $\beta$, followed by $C C$ and $A S L$. However, the uncertainty level of lead time changes the strength of the adjusting function of parameter $\beta$. See Table 5 .

Table 5 depicts the values and the relative change rates of three indicators under $\sigma_{L}=0, \sigma_{L}=$ $0.5, \sigma_{L}=1, \sigma_{L}=1.8$, and $\sigma_{L}=2$ with the parameter $\beta$ being $0.2,0.8$, and 1.8 , respectively. Different values of $\beta$ represent different order policies. IR1 indicates the growth rate of indicators when $\beta$ changes from 0.2 to 0.8 , while IR2 indicates the growth rate of indicators when $\beta$ increases from 0.8 to 1.8. Again, $C C$ represents the carbon cost, $A C$ represents the carbon cost, represents the average inventory cost, and $A S L$ represents the average service level. Table 5 shows that when the $\beta$ increases from 0.2 to 0.8 under fixed lead time, CC decreases by $0.15 \%, A C$ increases by $0.95 \%$, while $A S L$ increases by $0.07 \%$. However, when $\beta$ changes from 0.8 to $1.8, C C$ increases by $1.25 \%, A C$ increases by $8.35 \%$, and $A S L$ decreases by $0.24 \%$. Hence, it can be concluded that under fixed lead times, the policies of $\beta=0.2$ and $\beta=0.8$ have no significantly different impacts on the inventory system, but they are both better than the policy of $\beta=1.8$. When the standard deviation of lead time is 0.5 , the conclusion is similar.

When the standard deviation of lead time increases to $1,1.8$, and 2, the impacts of the different ordering policies on the system change. When $\beta$ increases from 0.2 to $0.8, C C$ decreases more than $3.2 \%$, which is much larger than when $\sigma_{L}=0$ or $\sigma_{L}=0.5$. increases by more than $4.3 \%$, except when lead time standard deviation is 1.8 . The increase, then, is only $0.36 \%$. The decreasing $A S L$ when $\sigma_{L}=1$, 1.8 , or 2 is also greater than that of fixed lead time. Therefore, $\beta=0.8$ is the better ordering decision criterion than $\beta=0.2$ When parameter $\beta$ changes from 0.8 to $1.8, C C$ and $A C$ both increase significantly. The average inventory cost $A C$ increases to $20 \%$. The $A S L$ also increases significantly from 1.80 to $3.6 \%$ when $\beta$ increases. While adopting the order policy of $\beta=0.8$, the inventory system becomes more 
stable, and its impact on cushioning lead time fluctuation is more efficient than that of policy $\beta=1.8$ Overall, it can be inferred that stochastic lead times does affect the regulation of the ordering decision.

Table 5. The values and the relative change rates of the three performance indicators.

\begin{tabular}{|c|c|c|c|}
\hline \multicolumn{4}{|c|}{$\sigma_{L}=0$} \\
\hline$\beta$ & $C C$ & $A C$ & $A S L$ \\
\hline 0.2 & 320.06 & 5045.32 & 0.9997 \\
\hline 0.8 & 319.58 & 5093.27 & 0.999 \\
\hline 1.8 & 323.57 & 5518.59 & 0.9966 \\
\hline IR1 $(\%)$ & -0.15 & 0.95 & -0.07 \\
\hline IR2 (\%) & 1.25 & 8.35 & -0.24 \\
\hline \multicolumn{4}{|c|}{$\sigma_{L}=0.5$} \\
\hline$\beta$ & $C C$ & $A C$ & $A S L$ \\
\hline 0.2 & 324.5 & 5792.86 & 0.9904 \\
\hline 0.8 & 321.29 & 5842.34 & 0.9871 \\
\hline 1.8 & 324.57 & 6498.21 & 0.98 \\
\hline IR1 $(\%)$ & -0.99 & 0.85 & -0.33 \\
\hline IR2 (\%) & 1.02 & 11.23 & -0.73 \\
\hline \multicolumn{4}{|c|}{$\sigma_{L}=1$} \\
\hline$\beta$ & $C C$ & $A C$ & $A S L$ \\
\hline 0.2 & 336.46 & 7762.43 & 0.9693 \\
\hline 0.8 & 325.53 & 8098.38 & 0.9546 \\
\hline 1.8 & 329.07 & 9345.13 & 0.9374 \\
\hline IR1 (\%) & -3.25 & 4.33 & -1.51 \\
\hline IR2 (\%) & 1.09 & 15.40 & -1.80 \\
\hline \multicolumn{4}{|c|}{$\sigma_{L}=1.8$} \\
\hline$\beta$ & $C C$ & $A C$ & $A S L$ \\
\hline 0.2 & 342.39 & 8610.34 & 0.9582 \\
\hline 0.8 & 327.95 & 8641.42 & 0.9455 \\
\hline 1.8 & 334.83 & $10,976.46$ & 0.9112 \\
\hline IR1 $(\%)$ & -4.22 & 0.36 & -1.33 \\
\hline IR2 (\%) & 2.10 & 27.02 & -3.62 \\
\hline \multicolumn{4}{|c|}{$\sigma_{L}=2$} \\
\hline$\beta$ & $C C$ & $A C$ & $A S L$ \\
\hline 0.2 & 344.08 & 8653.87 & 0.9575 \\
\hline 0.8 & 332.82 & 9053.59 & 0.9405 \\
\hline 1.8 & 339.33 & $11,152.49$ & 0.9092 \\
\hline IR1 (\%) & -3.27 & 4.62 & -1.78 \\
\hline IR2 (\%) & 1.96 & 23.18 & -3.33 \\
\hline
\end{tabular}

\subsection{Summary of Experimental Results}

Through the above experimental data analysis, we can see that:

(1) Stochastic lead times mainly affect the strength of the inventory system performance. The experimental results show that random lead time has an insignificant impact on the changing trend of each indicator. However, it greatly alters the values of the performance indicators. The sharper the lead time fluctuates, the higher the carbon cost and the average inventory cost of the system and the lower the service level. Thus, the overall performance of the inventory system decreases. The influence of lead time fluctuation on the three system performance indicators is different. Stochastic lead time significantly changes the average inventory cost, while it moderately changes the average service level. 
In addition, the average service level influenced by the lead time is slightly higher than the carbon cost. Furthermore, with the lead time turning to be more volatile, the inventory system performance continues to be weak, but at a slower pace.

(2) Optimizing order policy can mitigate the negative impact of stochastic lead times on the inventory system. Our simulation results show that under the same uncertainty of lead time, the impact of different ordering policies on the system's performance is different, especially when the lead time fluctuates greatly. This phenomenon demonstrates that the inventory system is more sensitive to the order policy when lead time varies. In other words, when the lead time is volatile, the supply chain system is sensitive, and the reverse adjustment function of ordering policies is strong. Hence, there exists appropriate order decisions to weaken the negative impact of lead time fluctuation on the supply chain.

(3) The fluctuation of lead time affects the regulation effect of order decisions on an inventory system. Ordering decisions have a moderate effect on the inventory system. However, when the lead time is random, the efficiency of adjustment changes. When the lead time fluctuation is mild, the inventory system is relatively stable, and an order decision does not cause the system to oscillate dramatically. The increase in lead time randomness brings a series of management problems, such as inventory control, procurement planning, order delivery, etc. Furthermore, it puts the supply chain system in a volatile state, which lowers the anti-interference ability of the system. Then, the order decision is the decisive factor in determining the system's performance. Moreover, the average inventory cost is mostly affected by order decisions, followed by carbon cost, and then average service level.

(4) Impacts on carbon cost are different for average inventory cost and average service level. In terms of performance indicator fluctuation with lead time variance, the value span of carbon cost is weaker than that of inventory cost and service level, but the change trend is more complex. This brings management challenges to balance the system's performance indicators in a low-carbon economy. Furthermore, when ordering decision-making is constrained by carbon policy, the carbon cost change can be taken as the reference point, so that inventory cost and service level can be balanced to maintain a minimum carbon cost.

\section{Conclusions}

Based on the APVIOBPCS model, this paper constructs a three-stage supply chain with the distributors as the focal firm in a periodic continuous review system. The traditional APVIOBPCS model primarily focuses on the impact of parameters of adjustment for inventory and work-in-process inventory discrepancy on supply chains under fixed lead time. However, in business practice, it is difficult to achieve a fixed lead time. Therefore, this paper makes an important contribution by introducing stochastic lead times into the basic APVIOBPCS model.

Our results show that stochastic lead time only affects the values, but not the trends of the inventory system performance indicators. Furthermore, the three performance indicators have different trends under different order policies. The negative impact of stochastic lead times can be dampened by the appropriate order policy. Moreover, the carbon cost curve is concave with regard to the order policy, while the inventory cost curve is continuously increasing, and service level curve is decreasing. Hence, when the managers make order decisions, they can take carbon cost change as reference point, and then balance inventory cost and service level to maintain a minimum carbon cost.

Carbon emission policies in many countries are still in the exploratory stage. In future studies, the optimal carbon emission policy may be identified. Future study can also focus on the interactions between carbon regulation policies and supply chain conditions, so that appropriate policies can be formulated to achieve green sustainable development.

Author Contributions: Conceptualization, Z.L. and X.C.; methodology, Z.L.; software, Z.L. and W.F; validation, Z.L., W.F. and E.Z.; formal analysis, Z.L., W.F. and E.Z.; investigation, W.F. and X.C.; resources, Z.L., Y.G. and E.Z.; data curation, W.F. and X.C.; writing-original draft preparation, Z.L. and W.F; writing-review and editing, E.Z., 
Y.G. and X.C.; visualization, E.Z. and X.C.; supervision, Y.G.; project administration, Y.G.; funding acquisition, Z.L. and X.C.

Funding: This work was supported by the National Natural Science Foundation of China (Grant No. 71761011), Ministry of Education Humanities and Social Sciences Project (Grant No. 17YJA630049), the Natural Science Foundation of Jiangxi Province (Grant No. 20171BAA208010), Major Projects of the National Social Science Fund (Grant No. 18ZDA093), the 13th Five-Year Plan Teaching Reform Project of Higher Education of Zhejiang (Grant No. jg20180428), and the Project of Education Department of Zhejiang (Grant No. Y201940902).

Conflicts of Interest: The authors declare no conflict of interest.

\section{Appendix A}

The relations among Equations (1)-(8) are connected by introducing $z$-transforms. The quantity of products that arrived $A Q$ in the period is related to the order quantity $O Q$ in the period is related to the order quantity $O Q$ :

$$
A Q(\mathrm{z})=\frac{1}{z^{\mathrm{L}}} \cdot O Q(z)
$$

The transformation function of demand forecasting $F Q$ can be obtained by using market demand $D$ :

$$
F Q(\mathbf{z})=\theta \cdot D(z)+(1-\theta) \cdot \frac{1}{z} \cdot F Q(z) \Rightarrow F Q(z)=\frac{z \cdot \theta}{\mathrm{z}+\theta-1} \cdot D(z)
$$

The inventory at the end of the period TINV is related to the initial inventory BINV and demand $D$, while the initial inventory $B I N V$ is determined by the terminal inventory of the previous period and the quantity of arrivals $A Q$ :

$$
\operatorname{BINV}(z)=\frac{1}{z} \cdot \operatorname{TINV}(z)+A Q(z)=\frac{1}{z} \cdot \operatorname{TINV}(z) \frac{1}{z^{L_{t}}} O Q(z)
$$

Therefore,

$$
\begin{gathered}
\operatorname{TINV}(z)=B \operatorname{INV}(z)-D(z)=\frac{1}{z} \cdot \operatorname{TINV}(z)+\frac{1}{z^{L_{t}}} O Q(z)-D(z) \\
=\frac{1}{z^{L_{t^{-1}}} \cdot(z-1)} \cdot O Q(z)-\frac{z}{z-1} \cdot D(z)
\end{gathered}
$$

Using the order quantity $O Q$ and the arrivals $A Q$, the work-in-process inventory WIP transform function can be obtained:

$$
W I P(z)=\frac{1}{z} W I P(z)+\frac{1}{z} O Q(z)-A Q(z) \Rightarrow W I P(z)=\frac{z^{L_{t}-1}-1}{z^{L_{t}-1} \cdot(z-1)} \cdot O Q(z)
$$

According to Equations (A1)-(A5), the system transform function is expressed by the correlation between order quantity $O Q$ and demand quantity $D$ :

$$
\begin{aligned}
& O Q(z)=F Q(z)-\alpha_{S} \cdot \operatorname{TINV}(\mathbf{z})+\alpha_{S L} \cdot L_{\mu} \cdot F Q(z)-\alpha_{S L} \cdot W I P(z) \\
& =\frac{z \cdot \theta}{z+\theta-1} \cdot D(z)-\alpha_{S} \cdot \frac{1}{z^{L_{t}-1} \cdot(z-1)} \cdot O Q(z)-\alpha_{S} \cdot \frac{z}{z-1} \cdot D(z) \\
& +\alpha_{S L} \cdot L_{\mu} \cdot \frac{z \cdot \theta}{z+\theta-1} \cdot D(z)-\alpha_{S L} \cdot \frac{z^{L-1}-1}{z^{L_{t}-1} \cdot(z-1)} \cdot O Q(z) \\
& \Rightarrow \frac{z^{L_{t}-1} \cdot(z-1)+\alpha_{S}+\alpha_{S L} \cdot z^{L_{t}-1}-1}{z^{L_{t}-1} \cdot(z-1)} \cdot O Q(z)=\left(\frac{z \cdot \theta\left(1+\alpha_{S L} \cdot L_{\mu}\right)}{z+\theta-1}-\frac{z \cdot \alpha_{S}}{z-1}\right) \cdot D(\mathbf{z}) \\
& \Rightarrow \frac{O Q(z)}{D(z)}=\frac{(z-1) \cdot z \cdot \theta\left(1+\alpha_{S L} \cdot L_{\mu}\right)-z \cdot \alpha_{S} \cdot(z+\theta-1)}{(z-1) \cdot(z+\theta-1)} \cdot \frac{z^{L_{t}-1} \cdot(z-1)}{z^{L_{t}-1} \cdot\left(z+\alpha_{S L}-1\right)+\left(\alpha_{S}-\alpha_{S L}\right)} \\
& =\frac{z \cdot\left[\theta\left(1+\alpha_{S L} \cdot L_{\mu}\right) \cdot(z-1)-\alpha_{S} \cdot(z+\theta-1)\right]}{(z-1) \cdot(z+\theta-1)} \cdot \frac{z^{L_{t}-1} \cdot(z-1)}{z^{L_{t}-1} \cdot\left(z+\alpha_{S L}-1\right)+\left(\alpha_{S}-\alpha_{S L}\right)} \\
& =\frac{z^{L_{t}} \cdot\left[\theta\left(1+\alpha_{S L} \cdot L_{\mu}\right) \cdot(z-1)-\alpha_{S} \cdot(z+\theta-1)\right]}{(z+\theta-1) \cdot\left[e^{L_{t}-1} \cdot\left(z+\alpha_{S L}-1\right)+\left(\alpha_{S}-\alpha_{S L}\right)\right]}
\end{aligned}
$$




\section{Appendix B}

\begin{tabular}{|c|c|c|c|c|c|c|c|c|c|c|c|c|c|c|c|c|c|c|c|c|c|}
\hline \multirow{2}{*}{\multicolumn{22}{|c|}{ Experinental data }} \\
\hline \multirow{2}{*}{$\sigma_{\mathrm{L}}$} & \multirow{2}{*}{ index } & \multirow{2}{*}{$\begin{array}{c}\text { variance } \\
\text { of index } \\
\text { values } \\
\end{array}$} & & & & & & & & & & & & & & & & & & & \\
\hline & & & 0.10 & 0.20 & 0.30 & 0.40 & 0.50 & 0.60 & 0.70 & 0.80 & 0.90 & 1.00 & 1.10 & 1.20 & $1.30 \mathrm{C}$ & 1.40 & 1.50 & 1.60 & 1.70 & 1.80 & 1. \\
\hline \multirow{3}{*}{0.00} & CC & 2.03 & 320.17 & 320.06 & 319.40 & 319.67 & 319.97 & 319.97 & 319.83 & 319.58 & 319.89 & 319.97 & 319.88 & 320.03 & 320.17 & 320.39 & 320.73 & 321.46 & 322.46 & 323.57 & 324.89 \\
\hline & co & & $5,034.57$ & $5,045.32$ & $5,046.22$ & $5,048.04$ & $5,048.61$ & $15,063.59$ & $5,079.80$ & $5,093.27$ & $5,108.30$ & $5,125.70$ & $5,143.74$ & $5,161.78$ & $5,189.04$ & $5,236.32$ & & & & & \\
\hline & $\Delta S L$ & 00 & 0.9999 & 0.9997 & 0.9997 & 0.9996 & 0.9996 & 0.9994 & 0.9992 & 0.9990 & 0.9988 & 0.9986 & 0. 9984 & 0.9983 & 0.9980 & 0.99 & 0.9973 & 0.99 & 0. & 0.9966 & 0.9969 \\
\hline \multirow{3}{*}{0.50} & $\mathrm{cc}$ & & 327.72 & 324.50 & 32 & 322. & 321.87 & 75 & 321.69 & 321.29 & 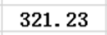 & 3 & 321.20 & 32 & 48 & 321.43 & 1 & 322.34 & 4 & ir & 326.34 \\
\hline & $\Delta C$ & 61 & $5,878.34$ & $5,792.86$ & $5,762.64$ & $5,754.02$ & $5,758.06$ & $6,782.81$ & $5,811.78$ & $5,842.34$ & $5,873.88$ & $5,915.20$ & $5,962.17$ & $6,018.77$ & $6,074.71$ & $6,132.54$ & $6,190.81$ & $6,273.70$ & $6,392.39$ & $6,498.21$ & $6,528.09$ \\
\hline & $\Delta \mathrm{SL}$ & 0.0000 & 0.9917 & 0.9904 & 0.9898 & 0.9894 & 0.9889 & 0.9883 & 0.9877 & 0.9871 & 0.9865 & 0.9858 & 0.9851 & 0.9842 & 0.9835 & 0.9827 & 0.9822 & 0.9816 & 0.9805 & 0.9800 & 0.9813 \\
\hline \multirow{3}{*}{1.00} & cc & 24.73 & 34 & 33 & 33 & 330.51 & 328.46 & 327.69 & 326.23 & 325. 53 & 325.34 & 325.25 & 325.13 & 325.14 & 325.16 & 325. & 326.17 & & & 329.07 & 329.74 \\
\hline & $\Delta C$ & & $7,802.66$ & $7,762.43$ & $7,815.96$ & $7,877.33$ & $7,935.98$ & $87,994.30$ & $8,047.19$ & $8,098.38$ & $8,154.58$ & $8,222.44$ & $8,304.44$ & $8,397.45$ & $8,512.15$ & $8,635.83$ & $8,759.02$ & $8,922.95$ & $9,134.97$ & $9,345.13$ & $9,567.63$ \\
\hline & ASL & 0001 & 0.9760 & 0.9693 & 0.9648 & 0.9617 & 0.9594 & 0.9575 & 0.9560 & 0.9546 & 0.9534 & 0.9521 & 0.9506 & 0.9491 & 0.9473 & 0.9455 & 0.9440 & 0.9420 & 0.9400 & 0.9374 & 0.9342 \\
\hline \multirow{3}{*}{1.80} & $\mathrm{cc}$ & & 2 & 3 & 335. & 59 & 33 & 32 & & & & 32 & 2 & & & & & & & & \\
\hline & $\Delta C$ & & & 8 , & 8,5 & 8,4 & $8,492.71$ & 18,5 & 8,5 & $8,641.42$ & & 8,85 & 9,02 & & & $9,754.58$ & & 10 & & & $11,289.10$ \\
\hline & $\mathbf{A S L}$ & 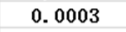 & 0.9660 & 0.9582 & 0.9544 & 0.9521 & 0.9503 & 0.9487 & 0.9472 & 0.9455 & 0.9435 & 0.9412 & 0.9382 & 0.9344 & 0.9308 & 0.9266 & 0.9222 & 0.9171 & 0.9141 & 0.9112 & 0.9087 \\
\hline \multirow{3}{*}{ 2. 00} & & 31.56 & 357.08 & 344.08 & 338.86 & 336.05 & 334.98 & 333.74 & 333.44 & 332.82 & 333.24 & 333.18 & 333.42 & 334.22 & 334.97 & 336 & 336.96 & 337.85 & 339.16 & 339.33 & 343.12 \\
\hline & $\Delta C$ & 627.83 & $8,859.03$ & $8,653.87$ & $8,618.86$ & $8,646.44$ & $8,720.57$ & $8,819.07$ & $8,926.23$ & 905359 & $9,179.40$ & $9,297.23$ & $9,412.10$ & $9,581.41$ & $9,813.65$ & $10,123.06$ & $10,388.07$ & $10,613.41$ & $10,845.51$ & $11,152.49$ & $1,448.31$ \\
\hline & $x^{\prime}$ & 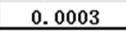 & 0.9653 & 0.9575 & 0.9534 & 0.9506 & 0.948 & 0.9455 & 9430 & 0.9405 & 382 & & & 0.9322 & 0.9291 & 0004 & 0.9209 & 0.9177 & 0.9146 & 0.9092 & \\
\hline
\end{tabular}

Figure A1. The results of computer simulation experiments with different order policies. 


\section{References}

1. Agi, M.A.; Nishant, R. Understanding influential factors on implementing green supply chain management practices: An interpretive structural modelling analysis. J. Environ. Manag. 2017, 188, 351-363. [CrossRef]

2. Diabat, A.; Kannan, D.; Mathiyazhagan, K. Analysis of enablers for implementation of sustainable supply chain management-A textile case. J. Clean. Prod. 2014, 83, 391-403. [CrossRef]

3. Giusti, R.; Iorfida, C.; Li, Y.; Manerba, D.; Musso, S.; Perboli, G.; Yuan, S. Sustainable and De-Stressed International Supply-Chains Through the SYNCHRO-NET Approach. J. Sustain. 2019, 11, 1083. [CrossRef]

4. Boute, R.N.; Van Mieghem, J.A. Global Dual Sourcing and Order Smoothing: The Impact of Capacity and Lead Times. J. Manag. Sci. 2015, 61, 2080-2099. [CrossRef]

5. Galal, N.M.; El-Kilany, K.S. Sustainable agri-food supply chain with uncertain demand and lead time. J. Int. J. Simul. Model. 2016, 15, 485-496.

6. Disney, S.M.; Maltz, A.; Wang, X.; Warburton, R.D.H. Inventory management for stochastic lead times with order crossovers. Eur. J. Oper. Res. 2016, 248, 473-486. [CrossRef]

7. Thorsen, A.; Yao, T. Robust inventory control under demand and lead time uncertainty. J. Ann. Oper. Res. 2017, 157, 207-236. [CrossRef]

8. Alhaj, M.A.; Svetinovic, D.; Diabat, A. A carbon-sensitive two-echelon-inventory supply chain model with stochastic demand. Resour. Conserv. Recycl. 2016, 108, 82-87. [CrossRef]

9. Giusti, R.; Manerba, D.; Bruno, G.; Tadei, R. Synchromodal logistics: An overview of critical success factors, enabling technologies, and open research issues. J. Transp. Res. Part E: Logist. Transp. Rev. 2019, 129, 92-110. [CrossRef]

10. Chao, C.; Zhihui, T.; Baozhen, Y. Optimization of two-stage location-routing-inventory problem with time-windows in food distribution network. J. Ann. Oper. Res. 2019, 273, 111-134. [CrossRef]

11. Schiffer, M.; Schneider, M.; Laporte, G. Designing sustainable mid-haul logistics networks with intra-route multi-resource facilities. J. Eur. J. Oper. Res. 2018, 265, 517-532. [CrossRef]

12. Zhao, Y.; Xue, Q.; Zhang, X. Stochastic Empty Container Repositioning Problem with CO2 Emission Considerations for an Intermodal Transportation System. J. Sustain. 2018, 10, 4211. [CrossRef]

13. Das, C.; Jharkharia, S. Low carbon supply chain: A state-of-the-art literature review. J. Manuf. Technol. Manag. 2018, 29, 398-428. [CrossRef]

14. Stopková, M.; Stopka, O.; L'upták, V. Inventory Model Design by Implementing New Parameters into the Deterministic Model Objective Function to Streamline Effectiveness Indicators of the Inventory Management. J. Sustain. 2018, 11, 4175. [CrossRef]

15. Ding, Z.; Xin, J.; Liu, Z.; Long, R.; Xu, Z.; Cao, Q. Factors affecting low-carbon consumption behavior of urban residents: A comprehensive review. J. Resour. Conserv. Recycl. 2018, 132, 3-15. [CrossRef]

16. Song, J.; Leng, M. Analysis of the single-period problem under carbon emissions policies. In Handbook of Newsvendor Problems; Springer: New York, NY, USA, 2012; pp. 297-313.

17. Chen, X.; Benjaafar, S.; Elomri, A. The carbon-constrained EOQ. J. Oper. Res. Lett. 2013, 41, $172-179$. [CrossRef]

18. Hovelaque, V.; Bironneau, L. The carbon-constrained EOQ model with carbon emission dependent demand. Int. J. Prod. Econ. 2015, 164, 285-291. [CrossRef]

19. Benjaafar, S.; Li, Y.; Daskin, M. Carbon footprint and the management of supply chains: Insights from simple models. J. Trans. Autom. Sci. Eng. 2013, 10,99-116. [CrossRef]

20. Diabat, A.; Al-Salem, M. An integrated supply chain problem with environmental considerations. Int. J. Prod. Econ. 2015, 164, 330-338. [CrossRef]

21. Park, S.J.; Cachon, G.P.; Lai, G.; Seshadri, S. Supply chain design and carbon penalty: Monopoly vs. monopolistic competition. J. Prod. Oper. Manag. 2015, 24, 1494-1508.

22. Konur, D.; Campbell, J.F.; Monfared, S.A. Economic and environmental considerations in a stochastic inventory control model with order splitting under different delivery schedules among suppliers. J. Omega 2017, 71, 46-65. [CrossRef]

23. Xu, Z.; Pokharel, S.; Elomri, A.; Mutlu, F. Emission policies and their analysis for the design of hybrid and dedicated closed-loop supply chains. J. Clean. Prod. 2017, 142, 4152-4168. [CrossRef]

24. Hoen, K.M.R.; Tan, T.; Fransoo, J.C.; van Houtum, G.J. Effect of carbon emission regulations on transport mode selection under stochastic demand. Flex. Serv. Manuf. J. 2014, 26, 170-195. [CrossRef] 
25. Sarkar, B.; Ullah, M.; Kim, N. Environmental and economic assessment of closed-loop supply chain with remanufacturing and returnable transport items. J. Comput. Ind. Eng. 2017, 111, 148-163. [CrossRef]

26. Arıkan, E.; Fichtinger, J.; Ries, J.M. Impact of transportation lead-time variability on the economic and environmental performance of inventory systems. Int. J. Prod. Econ. 2014, 157, 279-288. [CrossRef]

27. Chatfield, D.C.; Kim, J.G.; Harrison, T.P.; Hayya, J.C. The Bullwhip Effect-impact of stochastic lead time, information quality, and information sharing: A simulation study. Prod. Oper. Manag. 2004, 13, 340-353. [CrossRef]

28. Duc, T.T.H.; Luong, H.T.; Kim, Y.D. A measure of the Bullwhip Effect in supply chains with stochastic lead time. Int. J. Adv. Manuf. Technol. 2008, 38, 1201-1212. [CrossRef]

29. Boute, R.N.; Disney, S.M.; Lambrecht, M.R.; Houdt, B.V. Coordinating lead times and safety stocks under autocorrelated demand. Eur. J. Oper. Res. 2014, 232, 52-63. [CrossRef]

30. Saldanha, J.P.; Swan, P. Order Crossover Research: A 60-Year Retrospective to Highlight Future Research Opportunities. Transp. J. 2017, 56, 227-262. [CrossRef]

31. Chaharsooghi, S.K.; Heydari, J. LT variance or LT mean reduction in supply chain management: Which one has a higher impact on SC performance. Int. J. Prod. Econ. 2010, 124, 475-481. [CrossRef]

32. Li, J.; Liu, L.; Hu, H.; Zhao, Q.; Guo, L. An Inventory Model for Deteriorating Drugs with Stochastic Lead Time. Int. J. Environ. Res. Public Health 2018, 15, 2772. [CrossRef]

33. Spiegler, V.L.M.; Naim, M.M. Investigating sustained oscillations in nonlinear production and inventory control models. Eur. J. Oper. Res. 2017, 261, 572-583. [CrossRef]

34. Dejonckheere, J.; Disney, S.M.; Lambrecht, M.R.; Towill, D.R. Measuring and avoiding the Bullwhip Effect: A control theoretic approach. Eur. J. Oper. Res. 2003, 147, 567-590. [CrossRef]

35. Badole, C.M.; Jain, R.; Rathore, A.P.S.; Nepal, B. Research and opportunities in supply chain modeling: A review. Int. J. Supply Chain Manag. 2012, 1, 63-86.

36. Lin, J.; Naim, M.M.; Purvis, L.; Gosling, J. The extension and exploitation of the inventory and order based production control system archetype from 1982 to 2015. Int. J. Prod. Econ. 2017, 194, 135-152. [CrossRef]

37. Wang, J.; Wang, X. Complex dynamic behaviors of constrained supply chain systems. J. Syst. Eng. -Theory Pract. 2012, 32, 746-751.

38. Cannella, S.; López-Campos, M.; Dominguez, R.; Ashayeri, J.; Miranda, P.A. A simulation model of a coordinated decentralized supply chain. J. Int. Trans. Oper. Res. 2015, 22, 735-756. [CrossRef]

39. Cannella, S.; Ciancimino, E. On the bullwhip avoidance phase: Supply chain collaboration and order smoothing. Int. J. Prod. Res. 2010, 48, 6739-6776. [CrossRef]

40. Bao, C.; Zhang, S. Cold chain logistics joint distribution path optimization considering carbon emissions. J. Ind. Eng. Manag. 2018, 5, 95-100.

41. Li, L.; Yang, Y.; Qin, G. Optimization of Integrated Inventory Routing Problem for Cold Chain Logistics Considering Carbon Footprint and Carbon Regulations. Sustainability 2019, 11, 4628. [CrossRef]

42. Macchion, L.; Fornasiero, R.; Vinelli, A. Supply chain configurations: A model to evaluate performance in customised productions. Int. J. Prod. Res. 2017, 55, 1386-1399. [CrossRef]

43. Disney, S.M. Supply chain aperiodicity, bullwhip and stability analysis with Jury's inners. IMA J. Manag. Math. 2008, 19, 101-116. [CrossRef]

44. Zhou, L.; Naim, M.M.; Disney, S.M. The impact of product returns and remanufacturing uncertainties on the dynamic performance of a multi-echelon closed-loop supply chain. Int. J. Prod. Econ. 2017, 183, 487-502. [CrossRef]

45. Bijulal, D.; Venkateswaran, J.; Hemachandra, N. Service levels, system cost and stability of production-inventory control systems. Int. J. Prod. Res. 2011, 49, 7085-7105. [CrossRef]

46. Oliveira, E.M.D.; Oliveira, F.L.C. Forecasting mid-long-term electric energy consumption through bagging ARIMA and exponential smoothing methods. Energy 2018, 144, 776-788. [CrossRef]

(C) 2019 by the authors. Licensee MDPI, Basel, Switzerland. This article is an open access article distributed under the terms and conditions of the Creative Commons Attribution (CC BY) license (http://creativecommons.org/licenses/by/4.0/). 